\title{
Diseño de un díptico informativo para el paciente trasplantado renal
}

\author{
Maricruz Sánchez García - Sandra Rodriguez Real - Paula Ortiz OImo \\ Sandra Gálvez Elena - Antonio López Miravalles
}

Servicio Diálisis y Trasplante Renal. Hospital Germans Trias i Pujol. Badalona

\section{Sra. Directora:}

El trasplante renal se ha convertido en la actualidad en la terapia de elección en la Insuficiencia Renal Crónica al representar la mejor alternativa de tratamiento. Nuestro hospital es uno de los 7 autorizados en toda Cataluña para llevar a cabo el trasplante renal y uno de los 2, donde puede realizarse el trasplante renopancreático. Es un hospital básico para una población de más de 200.000 habitantes y el de referencia para más de 700.000. En el transcurso de los últimos 5 años se han llevado a cabo más de 100 trasplantes renales de los que más del $15 \%$ se han realizado a pacientes inmigrantes, por lo que de forma habitual nos encontramos con importantes barreras culturales y problemas idiomáticos que generan unos diagnósticos de enfermería que tienden a ser comunes en todos los receptores, tales como: ansiedad, riesgo de manejo inefectivo del régimen terapéutico, déficit de conocimientos y riesgo de infección.

Esta situación nos hizo plantearnos la necesidad de elaborar una guía actualizada, básica y visual para cubrir las necesidades de esta población. Pretendemos que ésta sirva para que, tanto el receptor como su cuidador principal, puedan continuar los cuidados en el domicilio. Intenta facilitar nuestra labor educacional al mejorar la comprensión de los cuidados, para conseguir

\begin{tabular}{|c|}
\hline Correspondencia: \\
Sandra Gálvez Elena \\
Unidad de Hemodiálisis \\
Germans Trias i Pujol Hospital \\
Ctra. del Canyet s/n \\
08916 Badalona (Barcelona) \\
sandruscky@gmail.com \\
\hline
\end{tabular}

los mejores autocuidados. La guía se ha titulado "Me han trasplantado un riñón, ahora ¿qué hago?" y para elaborarla nos planteamos los siguientes objetivos:

- Que el paciente aprendiera a identificar los signos y síntomas de alerta

- Que disminuyera la ansiedad provocada por la adaptación a su nueva situación de salud

- Incorporar la educación sanitaria post trasplante en su cultura

- Que aprendiera a manejar de forma efectiva la medicación inmunosupresora, y las medidas higiénico-dietéticas adecuadas a su nueva situación

- Que se reforzaran los conocimientos adquiridos durante el proceso de educación iniciado en el post trasplante inmediatos

- Concienciarlo de la responsabilidad del buen funcionamiento de su nuevo riñón.

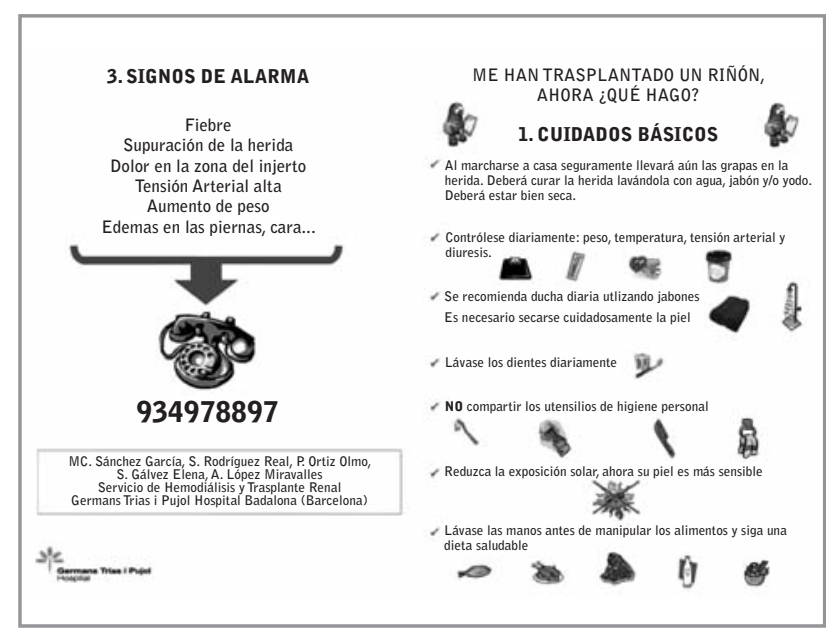

Figura 1. Cara A de la guía. 


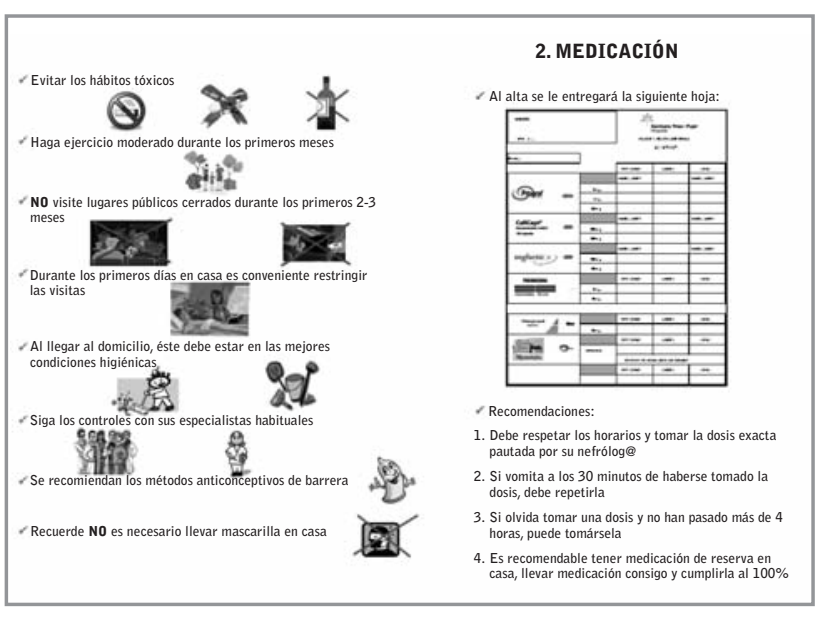

Figura 2. Cara B de la guía.

Para la elaboración de esta guía hemos estudiado las carencias y necesidades educativas de la población de trasplantados renales del Hospital Germans Trias i Pujol. Una vez evaluada estas necesidades, ideamos un documento con un lenguaje sencillo acompañado de ilustraciones universales para la fácil comprensión, evitando tecnicismos (figuras 1 y 2 ). Creemos que con los dibujos resulta más agradable visualmente y no precisa de un gran nivel de conocimiento y comprensión de nuestro idioma para entender qué deben hacer los pacientes cuándo Ilegan al domicilio. En la guía, se responde a las diversas inquietudes que el usuario tiene, dando respuesta a sus principales dudas, para ello la hemos divido en 3 apartados:

\section{Cuidados Básicos}

Se explica detalladamente los siguientes puntos:

- Cómo cuidarse la herida

- Controles que se deben seguir al alta

- Hábitos higiénicos

- Medidas de precaución a llevar tanto en el domicilio como en la calle

- Dieta recomendada

- Factores de riesgo a evitar

- Ejercicio físico recomendado

- Controles sanitarios
- Métodos anticonceptivos

- Utilización de mascarilla en el domicilio

\section{Medicación}

En este apartado se insiste en las principales recomendaciones que deben de tener presente: los horarios, las dosis y la forma de tomarse toda la medicación.

\section{Signos de Alarma}

Define los principales signos y síntomas de alarma para poder actuar de forma rápida e iniciar el tratamiento adecuado.

Creemos que dadas las necesidades actuales de nuestra población, la elaboración de esta pequeña guía ayudará al personal de enfermería en su labor de educación, a la vez que facilitará la capacidad del paciente para adaptarse a su nueva situación de salud, haciéndolos partícipes a la vez que protagonistas, consiguiendo así mejorar el cumplimiento terapéutico.

\section{Bibliografía}

1. Tornay Muñoz E, García González F. Guía para el niño trasplantado de riñón y su familia. Comisión de trasplantes. Hospitales Universitarios Virgen del Rocío. 2004.

2. Bloom R, Cardella C, Danovitch G, Roy First M, Germain $M$, Goral $S$, et al. Obteniendo su nuevo riñón, la realidad acerca del trasplante renal. Sociedad Americana de Trasplantes. 2003.

3. Escobar MJ, Guerrero González 0, Quintas Rodríguez J, Salvador Aguilar M. Guía para el paciente Trasplantado Renal: Las 20 preguntas más frecuentes. Comisión de Trasplantes de Hospitales Universitarios Virgen del Rocío. 2005. Coordinación de Trasplantes.

4. Castells M, Gatel S. Guía del Paciente Trasplantado Renal. Novartis Transplantation and Inmunology. 2005. 